\title{
COVID-19 Pandemic in Finland: Converting a Forced Digitalisation into an Opportunity
}

\author{
Kirsikka Riekkinen
}

COVID-19 pandemic challenged the Finnish society in terms of economic, institutional, and social aspects. Quick measures to support economic stability and institutional resilience were undertaken by the Finnish government. Private entrepreneurs could apply for funding to convert their products into digital format or develop digital platforms. The digitalisation of public services has been ongoing for years, but institutional change is slow and has tendency to resist the change. The sudden disruptive situation caused the change to speed up. The geographic location, sparsely populated country, and lack of digital skills especially among the oldest citizens have, however, brought challenges in the resilience of the society. While the preparedness for converting public and private services into digital format was high, the willingness or ability of citizens to use them have led to awareness of social resilience as part of recovering from the shock. For building and supporting the design of even better digital tools and services, the role of geographic data has become more important. Economic, institutional and social resilience rely heavily on this data, which emphasizes the importance of open and accessible data.

\subsection{Many Dimensions of Resilience}

Resilience overall is described as ability to recover from a shock. This spring has shown that resilience is needed on multi-level scale throughout our society. The complexity of the multiple levels can be simplified by dividing the problem into institutional, economic and social resilience $[1,2]$. Institutional aspect of resilience during this pandemic covers the public administration and decision-making in a situation where the traditional in-person, paper-based administrative decisions have decreased their role in decision-making. Economic resilience in this situation is discussed and visible all over the world, and recovering from depression will be one of the key questions in the success of resilience after the pandemic. Social resilience, on its behalf, has roots on the cultural background of people. Will there be personal tragedies, how relationships between people are recovering, what happens to the most vulnerable members of society? Next, I will examine these aspects together with the use of geographic information in the Finnish context.

We have seen a sudden change in social and working life. In order to remain resilient, this has risen the need for digitalisation in all the dimensions of resilience. Due to several restrictions on social distances and still to keep the stones of public services of society rolling, the public administration has been forced to take a leap towards forced digitalisation and distant working. This has been enabled by temporary laws. The public administration has been slowly introducing different digital services for a long time, but their popularity amongst citizens has not been huge. 
For example, electronic platform for property transactions was introduced already several years ago, but nevertheless, the vast majority of property transactions (97\% in 2018, according to National Land Survey) has been done by paper so far. However, the digital services gain popularity, especially in commercial services. According to one of the two largest grocery sellers in Finland, the rate of online grocery shopping has risen by $500 \%$ during the pandemic. The economic support activities for digitalising services reached up to 30000 companies. The regular ecommerce activities rose by $75 \%$ compared to previous year. And this all happened, even though there were no restrictions in opening times of physical shops. Digital services together with open access geodata have played a major role in economic resilience. Even though we have seen our economy declining, the government decided to invest in companies of every sizes to support the innovation of new digital services.

\subsection{The Importance of Open Geographic Data and Social Inclusion}

The topographic data in Finland provided by the National Land Survey is open, and it has been used in different new location based applications to provide new commercial services. At the same time the role of location data and maps has increased, especially due to changed consumer and customer behavior. Due to restrictions, restaurants were not allowed to serve food within their premises, but delivery services have gained interest. Online shopping for groceries has increased in average by $500 \%$ compared to last year. Half of these orders are delivered to home addresses, so we also have received new users for location information to find the route for delivery. From social resilience, the requirement for digitalisation is obvious. We see our relatives, friends and colleagues online. Social distancing has been the key in social relationships for the spring. There is a possibility to go beyond physical location, and having a glass of wine via Zoom does not seem such a silly idea anymore. But, again there are two sides of a coin: those who have already been in a risk to fall out of the society due to social distance, most likely do not have the possibility to use digital tools, and thus this situation increases social exclusion.

According to the Finnish experience, one key to resilience is trust towards decision-making bodies of the society. This requires the possibility to understand the data behind decisions restricting citizen's rights. We can say that we are going through times where open data plays a major role in both sustaining social peace and enhancing resilience, for example in terms of economic resilience, and maintaining trust towards decision-makers. It is crucial to maintain discussion about public decision-making, by opening the data behind the decisions for open access. But, the role of open geographic data could be even bigger in fighting the pandemic.

One of the globally most used strategy to stop the pandemic is the 'test, trace, isolate, support', and Finland makes no difference. The question of how to trace the exposed persons is urgent in this strategy. Ideas and openings of using geospatial data stored by mobile devices has been under discussion several times, and companies have started to develop such a method. But, we face the fundamental issue of person-related geographical data: who owns the data and can it be used for such purposes? Eventually, the question lies on public and private interests and rights. If the use of geographical data together with personal data is necessary to stop the pandemic, but it is violating basic human rights as restricting the freedom of a person, can we still use it? Coronavirus has proven to be transmitted in large crowds, and several countries including Finland, posed restrictions on number of people are allowed at the same place, same time. Geographical data could be used to track people's location and alert if too many are in a too small area. The fundamental question would lie on the legislation - there should be tools to take short-term legislation efficiently in to use, but the possibilities to ensure that this information is not used when it is no longer needed to stop the pandemic, is problematic.

For the large public, also professionals visualizing information of the pandemic on maps have had a major chance of influencing the mindset and behavior of people. GIS provides endless opportunities to steer people to different directions. Showing numbers on contagious people in different areas in dark red creates visions on people's minds. The fear of other people may be 
boosted by presenting most contagious areas on a map, when in reality the difference between areas might be small. This was evident when presenting number of confirmed infections in the capital, Helsinki. Maps can lie, and the responsibility for presenting the information not misleading is of utmost importance. Location information had also one totally new form or role during the past few months in Finland, and it was the distinction between 'us' and 'them', based on where people were living. We can say that the social dimension of location has had a totally new meaning.

\subsection{Lessons Learnt from Finland}

What have we learned during this spring and summer? People have changed their way of living forced by an external force to take a massive leap towards digitalisation. The society moved towards remote working, which will most likely to be the new normal from now on. This chance should be used to digitalise public administration and services, since citizens and other authorities are now much more ready to utilize these services. However, rapid digitalisation creates issues regarding for example data and privacy, especially regarding the location data. On the other hand, the meaning of open data in the society is getting more crucial to gain acceptance for the public decision-making processes. As a conclusion, we can say that eventually the battle against COVID-19 will end and it will leave marks to the society for good. We will be referring to these times as 'time before' and 'time after'. But what will remain, is the mindset of digitalisation, and also the mindset of how we all were in this together. Social distancing, with the help of tools of digitalisation, turned into social inclusion, supporting economic, institutional, and social resilience.

\section{References}

[1] Alberto Giacometti, Jukka Teräs, Liisa Perjo, Mari Wøien, Hjördis Sigurjonsdottir, Tuulia Rinne, A Giacometti, J Teräs, L Perjo, M Wøien, et al. Regional economic and social resilience: Conceptual debate and implications for nordic regions. Technical report, Discussion paper-Nordic Thematic Group for Innovative and Resilient Regions, 2018.

[2] Ron Martin, Peter Sunley, Ben Gardiner, and Peter Tyler. How regions react to recessions: Resilience and the role of economic structure. Regional Studies, 50(4):561-585, 2016. 
$\Longrightarrow$ Taylor \& Francis Taylor \& Francis Group

http://taylorandfrancis.com 